\title{
Innovative Integrated Architecture for Educational Games: Challenges and Merits
}

\author{
Rania Hodhod $^{1,2}$, Paul Cairns ${ }^{1}$, Daniel Kudenko ${ }^{1}$ \\ ${ }^{1}$ Computer Science Department, University of York, Heslington, \\ York, YO10 5DW, UK \\ \{rania.hodhod, pcairns, kudenko\}@cs.york.ac.uk \\ ${ }^{2}$ Faculty of Computer and Information Sciences, Ain Shams University, \\ Abbassia, Cairo, Egypt
}

\begin{abstract}
Interactive Narrative in game environments acts as the main catalyst to provide a motivating learning experience. In previous work, we have described how the use of a dual narrative generation technique could help to resolve the conflict between allowing high player student agency and also the track of the learning process. In this paper, we define a novel architecture that assists the dual narrative generation technique to be employed effectively in an adaptive educational game environment. The architecture composes components that individually have shown effectiveness in educational games environments. These components are graph structured narrative, dynamically generated narrative, evolving agents and a student model. An adaptive educational game, AEINS, has been developed to investigate the synergy of the architecture components. AEINS aims to foster character education at 8-12 year old children through the use of various interactive moral dilemmas that attempt the different student's cognitive levels. AEINS was evaluated through a study involved 20 participants who interacted with AEINS on an individual basis.
\end{abstract}

Keywords: Educational games, interactive narrative, intelligent tutor, character education, ill-defined domains.

\section{Introduction}

Educational games have the potential to provide intrinsically motivating learning experience to the learner. Interactive narrative in educational games is recognized as a valuable support for learning as it allows collaboration of humans and computers in the creation of innovative experiences where both sides are engaged in a meaningful construction process. It also helps make sense of experience, organize knowledge, sparking problem-solving skills and increase motivation. Within these environments, the rich generated stories allow a kind of unintentional learning process to occur through an engaging and appealing experience and the student is seen as an active participant in the construction of his own knowledge.

Such tempting characteristics of interactive narrative suggest it as a suitable teaching medium for ill-defined domains such as design, history, inter-cultural 
competence and ethics. An ill-defined domain is the one exhibits one or more of the following characteristics: (a) lack consistent, unambiguous, and generalizable solutions [1], (b) defense of different decisions is based upon different criteria and it often depends on how the solver conceptualizes the situation [2], (c) can not be described in a finite set of production rules [3] and (d) lack of defined rules that help in progressing in the solution path from the initial step to the final step [4].

The ethics domain is an important ill-defined domain where it affects oneself and others on a daily basis. The importance of the ethics domain is well recognized by schools as moral teaching is invited to be included in every possible curriculum [5]. Teaching ethics aims to develop child and adolescent awareness of social and moral responsibilities, so-called character education. Character education implies the widely shared, pivotally important, core ethical values, such as caring, honesty, fairness, responsibility, and respect for self and others along with supportive performance values that form the basis of good character, such as diligence, a strong work ethic, and perseverance [5]. Efforts have been made to find non-traditional ways of teaching such as role playing that helps students to transfer their knowledge and beliefs into actions [6], brainstorming moral dilemmas [7] and using interactive learning models [8]. Such efforts aim to help students' cognitive development by allowing them to pursue moral actions and see how their decisions affect other people and oneself in relation to others. However, these tools are not able to provide any empirical evidence on the development of the students' moral virtues in a general way. Nonetheless, learning in an ill-defined domain such as inter-cultural competence, as well as ethics, requires (at least) a heightened sense of self-awareness, an ability to self-assess, enhanced perceptive abilities and a proclivity to reflect on experience [9].

Generally, educational games suffer from trying to achieve two contradicting aims: provide a free narrative experience to the player student and the ability to track the learning process at the same time. Combining these two aims can be seen as a very hard task. In the past we investigated the possibility of combining more than one narrative technique in order to tackle this challenge. The dynamic narrative has been chosen for its ability to provide high player student agency and magnifies the feel of control through his ability to affect how the story unfolds. Scripted narrative has been used to construct the teaching moments (moral dilemmas) as it constrains the user agency and allows tracking and assessing the learning process. The dual narrative generation technique managed to produce free narrative that can seamlessly be interleaved with the teaching moments forming one continuous story.

This paper defines a novel architecture that assists the dual narrative generation technique to be effectively employed in an educational game environment. The educational game, AEINS, has been developed as a proof-of-concept. It aims to promote and leverage character education through a free user-system interaction and guided learning process. AEINS integrates interactive narrative and intelligent tutoring in order to have effective story telling underpinned by strong learning objectives. The next section motivates our work by presenting issues, controversies, and problems encountered in existing systems. Section 3 presents AEINS and its constituent modules. Finally, evaluation, summary and conclusion are presented in sections 4 and 5 . 


\section{Related Work}

Narrative-based educational games have been the subject of increasing attention. Work done in this area mainly focuses on embedding pedagogical activities in highly engaging, game-like interactions. There are various features used in edugames that meant to increase the effectiveness of these platforms such as: scripted narrative, dynamic generated narrative, evolving characters and student modeling. The following subsections aim to show how the current existed edugames employ these elements and highlight the synergy of these four features together in a single architecture.

Scripted Narrative. Different ideas have been proposed on the kind of interaction between the learning objectives and the game narrative content. Some edugames used scripted narrative in order to have control over the learner's experience. Scripted narrative is not as adaptive as planned narrative because it limits the learner's freedom in the environment [10] and requires an extensive amount of authoring work [11]. However, the scripted approach to interactive narrative can be seen as a 'must' to allow for learner assessment and automated guidance [1].

Scripted narrative was used in the TIME interactive drama prototype developed in the field of medicine [12]. Another edugame is StoryTeller developed in the literacy education domain [13]. The narrative in Storyteller is pre-defined by the children at the beginning of the play causing them to follow well-defined scenarios. A further edugame is BAT ILE developed to help learning binary arithmetic and logic gates [14]. In BAT ILE, the impact of the student's actions on the narrative is not obvious and a dramatic story is missed.

The scripted approach has also been used by the game-like environment ELECT BiLAT, a culturally sensitive negotiations simulator that trains high ranking military officers to achieve their military objectives in the field [1]. More edugames are the Tactical Language Trainer System (TLTS) that teaches trainees proper verbal, body language and cultural skills for different languages [15] and the TLCTS edugame developed to help people to acquire communicative skills in foreign languages and cultures [16]. The TLCTS edugame uses pre-authored descriptions of scenes, which identify characters, stage settings, and possible dialog exchanges between characters.

Dynamic Generated Story. Many edugames exhibit the presence of a dynamically generated story that allows the production of various stories each time the game is played. This kind of narrative is more adaptable than scripted narrative where the student actions are recognized in affecting how the story unfolds. However, some of these edugames do not take full advantage of storytelling potential seen in interactive drama applications. For example, the Mimesis edugame, developed to help middle school students to learn specific physical concepts, has the learning tasks represented in interactive narrative plans [17]. Each group of learning tasks is designed in a way that leads to one or more educational goal(s). Each learning task is a contained story in itself. Crystal Island is another edugame developed in the microbiology domain $[18,19]$. The authors take the same approach as ours in the way that the tutoring and narrative components interact together. 
The presence of continuous story allows the existence of narrative that 'glues' the generated learning objects together to form one continuous coherent story and preserve the dramatic tension. Another advantage can be seen in its ability to engage the learner and capture his attention through the presence of evolving agents whose personalities evolve over the interaction course with the game. Some edugames manage to have a continuous story such as the TEATRIX edugame [20] and the INTALE edugame [21]. TEATRIX is a learning environment designed to help children and their teachers in the whole process of collaborative story creation. In TEATRIX the narrative emerged from the children and the autonomous agents' interactions to form one continuous coherent story. IN-TALE is an edugame developed for military training skills. It integrates an automated story director and reactive autonomous agents in the context of a story-based military leader training scenario. However, this kind of generated story is not enough to ensure that the trainee is exposed to dramatic and pedagogically relevant situations in an appropriate and contextual order [21].

Other edugames either contain scenes or plots within which the learning objectives existed. A group of scenes or plots forms one story each time. For example, FearNot! a learning environment developed to to promote awareness about bullying behavior in schools $[22,23]$ and the ISAT edugame developed for the interactive training [24]. Conundrum is another edugame that allows learners to experience ethical decision making in realistic scenarios [25]. The ethical situations are encoded as acts and a sequence of scenes lead to a certain conclusion. Scenes used in FearNot!, plots used in ISAT and ethical situations in Conundrum are all separate disconnected stories that can be referred to as teaching moments. These teaching moments form the narrative elements (events) that generate a story as a sequence of events. The presence of continuous story allows highlighting the relationships among the narrative elements, which is considered as a key point for provoking active thinking and supporting meaning construction [26].

Evolving Agents. Narrative environments characterize by its rich worlds in which non-playing characters (agents) can inhabit. Life-like agents with evolving personalities increase the engagement and the realism existed in the game. Their direct reactions to the user actions, in addition to the change in their attitudes and personalities over the game unfold provide high engaging 'hawk'. Lately, FearNot! [11] shows big interest in achieving this kind of evolving characters through the whole game experience.

Student Modeling. Adaptation to individual student's needs can be seen as an advantage in any learning environment. Students could benefit from having tutorial guidance when playing educational games as they tend to perform better in more structured pedagogical activities [27]. Some edugames have recognized the importance of employing a student model such as ELECT BILAT [1], BAT ILE [14], TLTS [15], TLCTS [16], Mimesis [17], IN-TALE [21], ISAT [28] and ELEKTRA [29].

Riedl and Stern (2006) believe that narrative and interactivity are diametrically opposed [21]. In other words, coherent narrative and user agency are two seemingly conflicting requirements. In their work they use branching stories and believable agents, yet without assuring the pedagogical effect on the user. The problem becomes 
not only concerned with narrative generation and the player student agency but also with the ability to track the learning process and provide personalized feedback. A summary of the literature can be found in Table 1.

As seen from the above review, edugames used narrative to generate the game story and engage the student. They managed to offer personalized learning through the presence of either a tutoring model and/or a student model. However, there was always a need to compromise both entertaining aspects and educational aspects. Eventually, one aspect would override the other. Our previous work on the dual narrative generation addressed this issue, but it was not enough to offer the required personalized educational experience. This leads to the integration of more modules to assist this aim. The following section presents those modules and their roles on both the entertainment and the educational sides.

Table 1. A visualized summary on the different features of the above-mentioned edugames

\begin{tabular}{|c|c|c|c|c|c|c|c|c|}
\hline $\begin{array}{l}\text { Edtgame } \\
\text { Name } \\
\end{array}$ & $\begin{array}{c}\text { Linear } \\
\text { story }\end{array}$ & $\begin{array}{l}\text { Scripted } \\
\text { s:cry }\end{array}$ & $\begin{array}{c}\text { Dynanic } \\
\text { Generated Story } \\
\end{array}$ & $\begin{array}{c}\text { Continuous } \\
\text { S:ory }\end{array}$ & $\begin{array}{l}\text { Stiden: } \\
\text { Nodeling }\end{array}$ & $\begin{array}{l}\text { Pedagogical } \\
\text { Agent(s) }\end{array}$ & $\begin{array}{l}\text { Exolving } \\
\text { Agents }\end{array}$ & Ercluation \\
\hline ZLEC' B LAT & & • & & $\bullet$ & & & & \\
\hline Fa:Not! & & & $\cdot$ & & & & $\cdot$ & $\cdot$ \\
\hline Mines.5 & & & $\cdot$ & & $\cdot$ & $\cdot$ & & \\
\hline TEATRIX & & $\cdot$ & & & & & & $\cdot$ \\
\hline 3.AT ILE & $\bullet$ & & & & $\cdot$ & & & - \\
\hline n-TPLE & & $\cdot$ & & $\bullet$ & & & & $\cdot$ \\
\hline Story Zedler & & & & • & & & & $\cdot$ \\
\hline T.ME & & • & & & & & & $\cdot$ \\
\hline Crysta sland & & & $\cdot$ & & & & & - \\
\hline SAT & & $\bullet$ & & & & & & - \\
\hline TLCIS & & & $\cdot$ & & $\bullet$ & & & - \\
\hline Corundrum & & $\cdot$ & & & & & & \\
\hline TLTS & & & $\cdot$ & & $\cdot$ & & & $\cdot$ \\
\hline ZLEKTRA & & $\cdot$ & - & & $\cdot$ & $\cdot$ & & - \\
\hline AZINS & & - & $\cdot$ & $\bullet$ & $\cdot$ & $\cdot$ & $\bullet$ & $\cdot$ \\
\hline
\end{tabular}

\section{AEINS}

The aim of this paper if to focus on the various modules needed in order to help the dual narrative generation technique to achieve its aims in an adaptive educational game environment. In other words, not only engages the user but also act as an adaptive learning medium.

Adaptation is an important requirement in learning environments as it provides personalized learning process and personalized feedback which are important for effective education. In order to provide this kind of intelligent tutoring, the following modules are needed: a domain model, a student model and a pedagogical model. Moreover, to provide an interesting engaging environment a story module is also required. All these modules have been integrated in a single architecture that attempts to address the shortcomings of the existing systems.

At the first glance, the integration of these modules together is challenging. Difficulties appear in interleaving the learning objects in the STRIPS-Planner generated plans without harming the dramatic effect and the events flow. When and how frequent feedback should be provided is another struggle, in addition to the 
agents' autonomy and their pedagogical role in delivering learning. More challenges have been found in scripting the learning objects and representing the various existed modules. The next subsections illustrate the techniques used in order to face these challenges. In order to evaluate the developed architecture the educational game, AEINS, has been developed as a proof of concept. Qualitative and quantitative evaluations have been done to assess AEINS.

AEINS is an adaptive educational game that aims to help in character education. AEINS is a problem solving environment that engages 8-12 year old children effectively in interactive moral dilemmas in order to practice moral virtues. AEINS has been designed as an endogenous game, where the content material is intimately tied in with the game play. AEINS main aim is to allow students to move from the making moral judgments state to the taking moral actions state, from the knowing state to the doing state, which we consider a very important step in moral education.

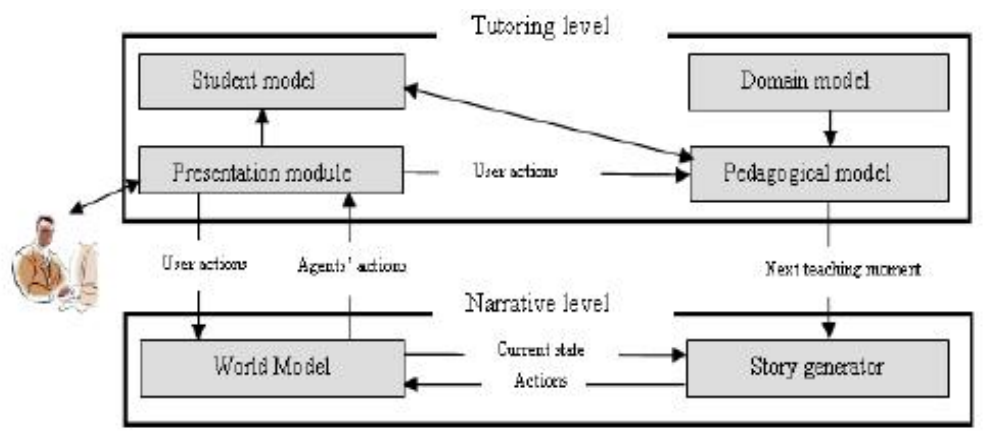

Fig. 1. AEINS architecture showing the various modules and their interactions.

\subsection{The Domain Model}

The domain model describes the various concepts (i.e. values) in the ethics domain and their relationships. One part of the model defines the principles of character education [30] and represents their relationships and dependencies. Prof. Helen Haste, Emeritus Professor of Psychology, has been consulted on the validity of the designed model. Prof. Helen agreed that the represented model is quite a clear representation of what one might call common sense and popular views. She added that the model can be used by all means as a basis for developing our game.

Frame knowledge representation has been used to represent the model for the following reasons: firstly, it allows arranging domain knowledge at different granularities, secondly, it is well-suited for the representation of schematic knowledge, and thirdly, it requires no costly search processes. Each frame has its own name and a set of attributes or slots, which contain values; for instance, the frame for trustworthy moral virtue (root concept) have slots that corresponds to sub-values (subskills) that should be mastered in order to consider the main value (skill) mastered such as be-honest and not-lie values. Lastly, frames representation provides a flexible 
model as it allows partial ordering of the dependencies and relationships between the domain concepts. In this way, it leaves 'room' for the pedagogical model to choose the next concept to present the student with based on the current student model.

The second part of the domain model comprises of a teaching moments repertoire. The teaching moments can be thought of as a variety of ethical problems that require tough decisions. The idea behind the current design of the teaching moment is based on analyzing various moral dilemmas and transforming them to story graph structures, then specify decision points that reflect specified skills. The teaching moments allow the use of an intelligent tutor to track the student's actions and assess them in the form of a step-by-step follow-up. An example of a graph structured teaching moment is shown in Fig. 2, the variables has been instantiated to specific names and places to simplify the visualization process. Ideally, each teaching moment path/branch describes a story in which the protagonist is the user in the role of making moral decisions. The teaching moments allow students to pursue different procedures for solving the problem based on the student's perception and interpretation of the nature of the problem. The student's understanding gained through this process is situated in their experience and can best be evaluated in terms relevant to this experience.

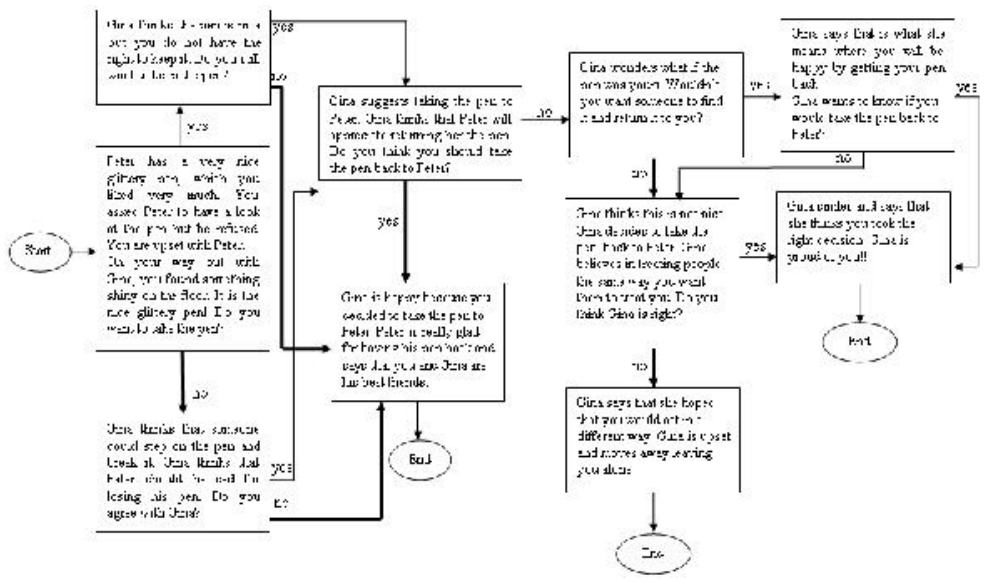

Fig. 2. An example of a graph structured dilemma (a teaching moment)

Although the different branches of every teaching moment are pre-defined, each teaching moment exhibits variability by allowing different characters and places to present the teaching moment depending on the story-world state. Each teaching moment represents a part of the whole story and focuses on teaching a specific moral virtue in a way that the concept mastery is established within. Each teaching moment has certain prerequisites that must be fulfilled before the execution of the teaching moment takes place. Manipulating a teaching moment's priority is done via represented rules as follows:

Trigger: teaching moment $\mathrm{TM}_{1}$ has not been presented

and teaching moment $\mathrm{TM}_{2}$ has not been presented 


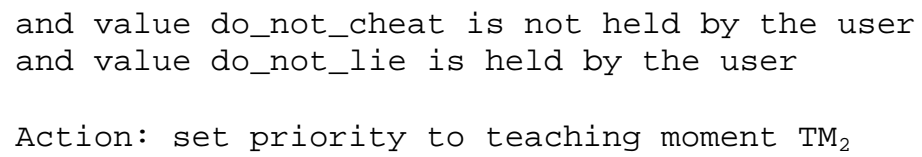

The representation denotes that if (a) a specific pattern of teaching moments $\left(\mathrm{TM}_{1}\right.$ and $\mathrm{TM}_{2}$ ) has not been presented to the student yet and (b) the student holds certain values (do_not_cheat) and does not hold others (do_not_lie), the action part of the rule executes (teaching moment $\mathrm{TM}_{2}$ has priority over teaching moment $\mathrm{TM}_{1}$ ). If several rules satisfied their premises, this result in having more than one teaching moment to present, then any of them would be appropriate enough to be presented next to the student.

\subsection{The Pedagogical Model}

The pedagogical model aims to adapt instruction, monitor and evaluate the student's actions. The model is developed in the form of production rules. These rules are used to give the system specific cognitive operations to reason about the student and the teaching process. In order to design the pedagogical model, the problem structure and what exactly needs to be modeled need to be specified. With ill-defined problems, development is a change in the way a person thinks and not merely a case of acquiring more knowledge. Therefore, what really matters is how the student would perceive the problem, act on it, observe consequences and apply what he/she learned later (in similar situations). The model specifies how the student would ideally use the system and how the system should assess the student's skills and update the student model accordingly.

The pedagogical model adapts instruction following a model of human tutoring expertise that balances motivational and cognitive goals. The Socratic Method is used as the teaching pedagogy weaved within the narrative and provides an adequate medium to enforce learning the required skills and reinforce positive actions. It triggers lively discussion and helps students make choices based on what is right instead of what they can get away with. According to this model, the teacher asks a series of questions that leads the students to examine the validity of an opinion or belief. This is a powerful teaching method because it actively engages the student and encourages critical thinking, which is just what is needed in examining ethics, values, and other character issues. It allows an appropriate amount of choices during illstructured and authentic investigations that lead to the development of inquiry skills [31].

The Socratic Method displays its strength when students make a bad choice. Through discussion, students should then be forced to face the contradictions present in any course of action not based on principles of justice or fairness. This method requires a delicate balance between letting the students make decisions, and demonstrating the limits in their reasoning. Finally, raising the stakes and introducing consequences is a tactic followed if the student sticks with the unethical choice. For example, if we would like students to investigate the effects of stealing, we could pose the problem of shoplifting and ask what they would do if they are the owners. In Lynch et al. [32], it has been shown that even in domains where it is impossible to 
make sharp distinctions between good and bad solutions due to the lack of ideal solutions or a domain theory, solution differences are meaningful. In our opinion, the students' answers to a Socratic Dialogue are also meaningful and reflect their own beliefs and thoughts.

The pedagogical model runs the educational process effectively without interfering as a tutor; the whole experience along with provided feedback is tailored in the story context. Since the educational object is in the narrative form, the end of this story depends on the student's actions and choices during the learning course. The final event of the story corresponds to a summative feedback that relates the student's actions to the end result.

\subsection{The Student Model}

Student modeling aims to provide a personalized learning process based on the current student's skills. The student model in AEINS is a complex form of the overlay model represented in the form of rules, associated with certainty confidence, to allow access to sufficient data to permit reliable inferences about the student's beliefs. The model is a mix of implicit, structural and background student models. However, this is not an automated model but it is the pedagogical model authority to update the student model under those themes. Nonetheless, the model also constitutes rules that allow inferring more knowledge about the student's cognitive state in order to enrich the model. The model assumes that the student knowledge is a subset of the expert's knowledge and aims to expand the student knowledge until it matches the expert's. AEINS initializes the student model through some preliminary actions that are designed specifically to help infer an initial model of the student and builds a model of the student's learning process. The general inference rules take this form:

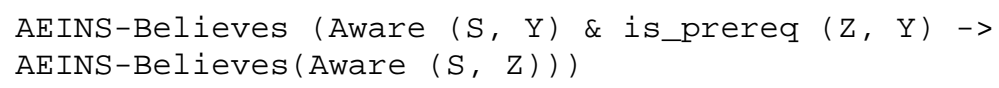

\subsection{The Presentation Module}

The presentation module handles the flow of information and monitors the interactions between the user and the system. Keller's ARCS model [33] provides four classes: Attention, Relevance, Challenge, and Satisfaction/Success that has been considered while designing the edugame interface. This model mainly aims to gain and retain the student's attention and to understand implicitly how the activities relate to their current situations. In addition to making use of surprise an uncertainty is attached with presenting a problem or new situation which helps in capturing the student's attention. At the awaken stage, the interface itself is designed in a way that captures the student's attention. The playing characters personalities evolve over time, which make their reactions vary every time with respect to their current personality. The variance of the narrative experience is engaging in itself, helps to capture the attention of the student and creates new experiences. At the explain stage, feedback 
and explanations are given to student within the story context. This fosters some meta-cognitive skills, such as self reflect, data analysis and linking causes and effects. At the Reinforce and Transfer stages, the student has the freedom to trace back his previous actions and the virtual characters' actions. Again, the student is indirectly forced to self reflect and link causes and actions in order to see what walks him to this particular end. As a result, the student is forced to make a conscious choice in terms of ethics.

\subsection{The Story World Module}

The game nature of AEINS allows the existence of non-playing characters acting as pedagogical agents and various objects in the AEINS story world. The purpose of pedagogical agents is not to perform tasks for users or to simplify tasks, but rather to help users learn how to accomplish tasks [34]. They aim to increase problem solving effectiveness by providing students with customized advice [35]. The pedagogical agents in AEINS are semi-autonomous where on one hand they are able to act and react according to their state and the current world state. On the other hand, the story generator can dictate them, when required, what to do in order to preserve the dramatic line and the educational targets. The presence of a continuous story with characters personalities evolving during the story unfold helps the mental and emotional engagement of the student.

The AI of the non-playing characters is represented in the form of rules, these rules can be modified during the story unfold as a result of certain actions. For example, a character who is a friend to the student can become an enemy as a result of a student action. Or a holder of unethical moral virtue character can change to be a holder of a good moral virtue as a result of some interactions with the surrounding world.

The student and the agents are responsible for the story unfold where it is generated based on their actions. When it is time to present a teaching moment, the currently involved agents in the main story will take the corresponding roles (that fits their current personalities and relationship to the student). If there exist a role that is still needed to be occupied or an agent is not capable to take that role, the story world with the assistance of the story generator will allow the inclusion of another agent smoothly through the narrative. Once the scene is set, the teaching moment starts.

As mentioned previously, the predominant teaching pedagogy is the Socratic Method. The holder of the good moral virtue uses the Socratic Voice to provide discussion, hints and feedback to the student. The text dialogue produced encourages the student to think critically in order to solve the discrepancies encountered in the moral situation(s) he is facing. In addition, students have opportunities to choose among different options and to reason about the criteria lead to the chosen option [36]. When the teaching moment ends, the student and the agents are free to act again influencing the main story line. The story world receives the required actions to be executed by different agents and pass this information to the presentation module to be shown to the student. An example of the story world representation is as follows:

place ("house")

place ("library") 


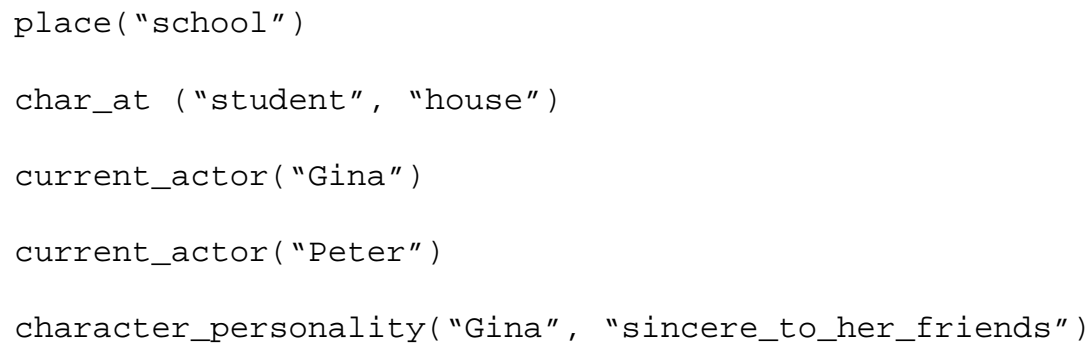

\section{Evaluation}

AEINS is intended to be evaluated for the following aspects: design goals, adaptation, games' features, technical features, social aspects and educational outcomes. Evaluation in the context of learning technology can be described as a process through which the information about usability of a system is gathered in order to improve the system or to assess a completed interface, and the evaluation methods are procedures for collecting relevant data about the operation and the usability of the system [37]. When a novel learning technique is proposed and implemented, it is necessary to compare it with other similar techniques, if possible, to gauge how it improves on previous results [38]. To the extent of our knowledge, AEINS is the only edugame developed to teach children in the ethics domain, therefore a comparison study to other similar platforms is impossible. However, the utilization of individual aspects in AEINS can be compared to others who made use of the same aspects or at least according to the literature definition for these aspects.

\subsection{Evaluation of Design Goals}

Evaluation of any system is the way to prove its effectiveness. The need for evaluation especially arises when a new design paradigm is presented. In order to evaluate the design goals, formative and summative evaluation could be followed. Formative evaluation seeks to identify aspects of a design that can be improved and summative evaluation seeks to gauge a design outcome. A good evaluation method or approach is the one able to play both of these evaluation rules [39]. Another evaluation methods is the pay-off evaluation, which has more to do with the design aspect, the main problem in this evaluation technique is that if a fault is discovered in the design, there is little systematic basis for attributing shortcomings or strengths to specific aspects of the design [40]. To overcome this difficulty, it is useful to address each goal separately and see how the design manages to satisfy the required goals. Intrinsic evaluation can be seen as the suitable method to use, it is concerned with design goals and is interested in the implicit goals embodied by aspects of a design, and makes value judgment about these goals. 


\subsection{Intrinsic Evaluation}

Intrinsic evaluation aims to verify that the design goals has been achieved through achieving the following:

- The development of a generic architecture based on learning theories. The architecture should exhibit the following:

- The creation of a continuous generated narrative that allows the presence of evolving characters.

- The integration of an intelligent tutor that makes use of a student model to attempt to solve the bandwidth problem and allows adaptation.

- Addressing the student agency versus tracking the learning process problem. - The use of the Socratic Method as the teaching pedagogy that helps in developing moral reasoning.

- Solving classroom problems such as adaptation to individual students and helping shy students to express their beliefs.

The first part considers the architecture design, which is based on the idea of using interactive narrative and problem based learning that suits many ill-defined domains like those mentioned previously. It is generic in the sense that it can be utilized in any system that aims to teach in ill-defined domains such as ethics and citizenship, history, English literature or social behaviours. In addition, educational theories, such as Gagné's nine events, which have been considered during the design phase, whereas Keller's ARCS model has been considered in designing and implementing the presentation model. Moreover, the architecture manages to achieve the goals set for successful educational games.

One aspect of the designed architecture lies in the ability of the story generator to produce a dynamic continuous story at run time that allows the interleaving of graph structured narrative(s). This kind of narrative acts as the teaching moments that allows problem solving, learning by practicing and mastering the skills through repetition, yet applied in various situations. The continuous story allows the presence of nonplaying characters whose personalities evolve and change as the story unfolds. They help in providing realism and believability to the story world and helps in supplying education to the student especially through use of the Socratic Voice. The evolving characters help also to provide engagement and commitment to the edugame virtual world.

The third aspect will be verified later in subsection 4.5. The fourth contribution deals with the agency problem found in the existing edugames, where the generated narrative in these edugames either produced by continuous planning and loses some aspects of the educational process such as keeping track of the learning process and being able to assess the learner or produced by graph planning that constrains the learner's freedom in order to maintain the educational goals. AEINS succeeds in overcoming this by integrating both graph planning and continuous planning approaches in generating the edugame story, which is a unique feature of AEINS. The former has been used in structuring the teaching moments and the latter was used to 
generate the story that links the teaching moments together and forms a long continuous story. \% that accommodate the Socratic Dialogue.

The third aspect deals with the teaching in AEINS. AEINS follows the constructivist teaching approach, where it is not merely teaching the participant about a process or concept undertaken by an ethics teacher, but rather allows him to experience the process directly. AEINS has strong learning objectives underpinned by effective storytelling, where it uses stories and interactive narrative as a source of inspiration and direction for moral conduct. Learners are involved in moral dilemmas that help them to express their own characters through problem solving, decision making, and conflict resolution present in these dilemmas. This kind of problem solving and decision making allows the learner to learn about basic human values including honesty and kindness. The following contribution of AEINS lies in the use of the Socratic Method as its teaching pedagogy in order to help the learners to discover for themselves what knowledge gaps they may have, along with skills they may need to develop. The ability of AEINS to provide learning and/or develop the students' moral reasoning will be discussed in the empirical evaluation section.

The final contribution is concerned with solving real-life classroom teaching problems. These problems are tackled through using computers in general and using AEINS in particular. AEINS succeeds to overcome the classroom problems, where it offers learning at the participant's pace, the required privacy and the safe environment within which children can explore. It allows the inclusion of many different dilemmas that the child can interact with and learn from. Most importantly it offers adaptation that provides personalized teaching and feedback. Moreover, the learner is able to interact with the virtual environment, receiving reactions during the interaction course and afterwards about what has happened; form his own hypothesis and re-interact with the environment, seeing what effect he or she gets and finally treats this effect as feedback and accepts or rethinks his or her original hypothesis. By doing this, AEINS helps the learners to move from the state of making moral judgments to the state of taking moral actions, from the knowing state to the doing state, which we consider a very important step in moral education.

AEINS has been tested for its longest learning path wherein experts play the role of users in order to test for code coverage. In this case the student model was initialized with all the moral virtues assigned as 'not mastered' and during the interaction course with AEINS, there was no indications that the learner was involved in concept formation; in other words the learner shows misconception and persistent activity while interacting with the teaching moments. Based on this attitude, the pedagogical model meant to present all the dilemmas related to the misconceptions. In conclusion, AEINS successfully provided the longest learning path when required.

Although results from the analytical analysis partially confirm the hypothesis of the thesis, empirical evaluation is still needed to fully judge the contributions of this thesis. The next section evaluates AEINS against various game aspects. 


\subsection{Adaptation in AEINS}

Evaluation of adaptive systems can provide feedback that can be used to modify the adaptation strategies of the system itself. The adaptation decision-making phase can help in assessing the system's ability at building student models and the supply of a personalized learning process based on these models. This section discusses the importance of the student model and provides evidence for its positive role from the study of the participants' $\log$ files. However, we would start with the assumptions upon which we judged the efficacy of the model as follows:

- The student modeling has a positive result if the process is able to determine correctly the participant's misconceptions or missing conceptions underlying unethical action or choice and provides the appropriate feedback.

- The student modeling has a negative result if the process fails or is unable to determine the participant's misconceptions and consequently does not provide the right feedback corresponding to the participant's actions.

The level of success of the student model component depends on how comprehensive the implemented rules are and the complexity of the rules for determining the participant's misconceptions. From the study of the log files, it has been found that the presence of the student model allowed the presentation of the appropriate teaching moments' according to the participant's needs; the rest of the teaching moments were not presented because the participant's learning level did not require them. On the other hand, obviously, with the absence of the student model the teaching moments would be presented in a specific order to all the learners without any considerations to their differences and regardless of their needs.

A well designed student model offers good help for a class instructor to use in order to know the participants in his/her class in a better way. It also gives the instructor a guide to the most suitable dilemma(s) to prepare for the next class; a dilemma that addresses the misconceptions of most of the class participants. AEINS was able to produce final summarized report for every single participant that gave information about the student's level and provided a summary about the whole experience. The report also contained information about the teaching moments experienced by the participant, the participant's actions and the system's evaluation for each action. Moreover, the report reflected on the acquired skills of the participants associated with a confidence factor representing the system's confidence that the participant had acquired certain skill(s). With this evidence about how the student model worked in AEINS, we argue that the student modeling has a positive result of the process.

In the next section, we will present a deeper study that has been done to the participants' log files. 


\subsection{The Analysis of the $\log$ Files}

We have studied the participants' log files to investigate the reasoning paths taken during their interaction with AEINS. The main risk when performing experiments \slash evaluation for an educational game that seems to judge the participant personality lies in the fact that the participants may always try to pick the right choices as a result of being observed, for example always not to lie. In other words this means that the majority of the participants would be in the Right-Right cells. Log files were studied carefully in order to examine this theme. Fortunately, for our purposes, this is not the case as can be seen from the tables $\backslash$ footnote $\{R-R$ denotes both an initial and final Right action (student adheres to the right choices). R-W-R denotes an initial Right action, followed by a Wrong action(s) and a final Right action. W-W denotes an initial Wrong action and remains devoted to it to the end resulting in a final Wrong action. W-R denotes an initial Wrong action and final Right action $\}$ below.

Table 2. The reasoning baths for teaching moment 1

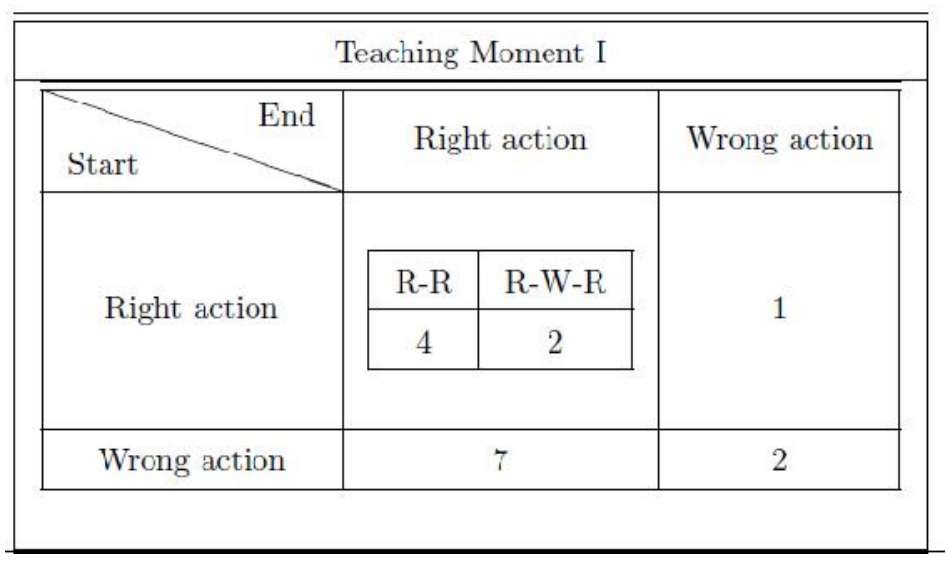

The above table provides interesting results. The variance in the start states between right and wrong shows that the participants' felt free in making their initial choices. On the whole the tables show that pedagogical model manages to present the student with the appropriate teaching moments that challenge the participants as more than $50 \%$ of the time the participant would go with the wrong choice.

Most of the participants take the wrong action at the start of the teaching (36 out of 71 interactions). The majority of the participants express care towards their friends to the extent they can do something which obviously seems to be wrong, however when they realize that what they did was not right they tend to change their behaviour and adhere to the right choice ( 31 out of 71 interactions). The rest adhere to the wrong choice even after being involved in the Socratic Dialogue (5 out of 71 interactions).

Other participants appear to pick the right choices and adhere to them to the end. It is fairly hard to exactly identify the reasons for this. It can be either a reflection of 
their own personalities or because of their awareness of what is expected from them in this experiment or could be they value their friendship very strongly or even just exploring the consequences of their actions (20 out of 71 interactions). Others started with taking the right action, however they seem to re evaluate their decision based on the consequences occurred, for example their friend could be upset so the participant's altered their behaviour to please their friend and stick to a wrong choice (4 out of 71 interactions).

What is also interesting is the multiple change of behaviour within the same teaching moment where the participants start with picking the right choice then alter their behaviour for their friend's sake (take a wrong action) then once again after being involved in the Socratic Dialogue they managed to discover the incorrectness $\backslash$ slash contradictions existed in their actions. Eventually, those participants mange to end with the right choice (11 out of 71 interactions). The above results can be visualized in the charts below.

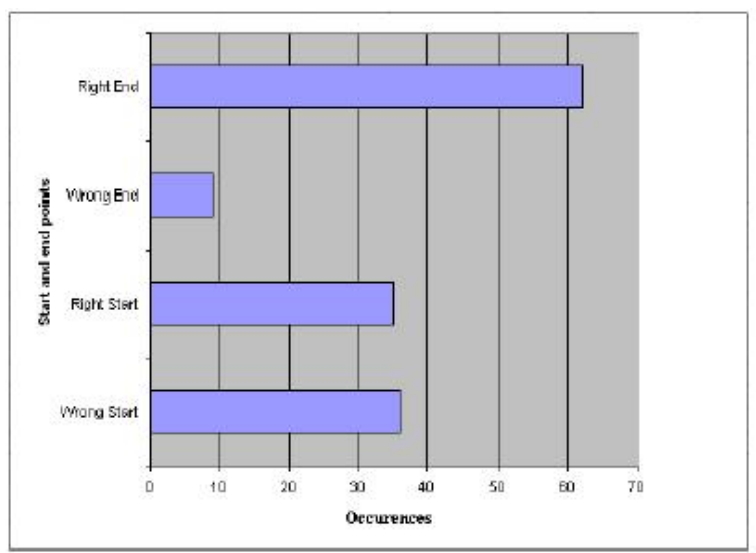

Fig. 3. The occurrences of the right and wrong choices

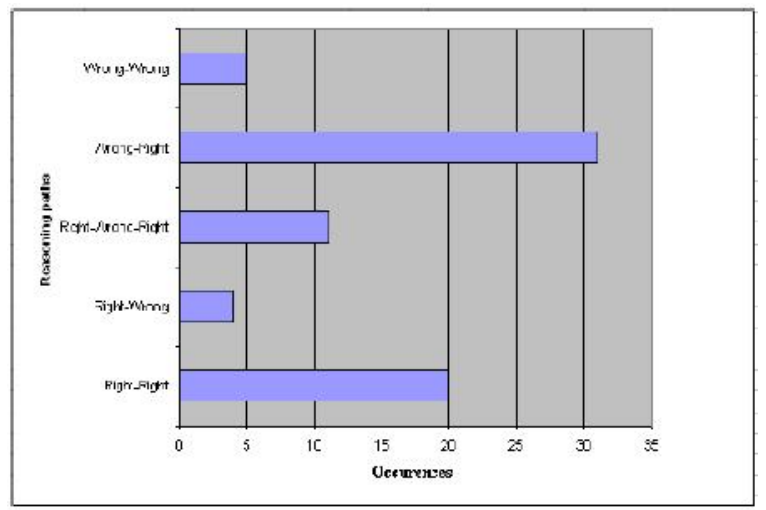

Fig. 4. The occurrences of different cognitive paths 
Fig. 3 shows the $50 \%$ of the time chances the participant has for their initial choice. It also clarifies that the majority of the occurrences end with the right choice. Fig. 4 shows that the majority of participants were presented with the appropriate teaching moments that were able to challenge them based on the pedagogical model's decisions. This also indicates the validity of the student model representation that supplies knowledge to the pedagogical model. As seen in Fig. 4, there occurred 36 initial wrong actions and 31 final right actions for those interactions. This shows that the system successfully aided around $86 \%$ of those who initially made the wrong choice to discover the contradictions in their course of actions and make the right choice at the end.

\subsection{Empirical Evaluation}

Gena (2005) mentioned that qualitative methods of evaluation are seldom applied in the assessment of user adaptive systems [41], however for the purpose of this study the qualitative evaluation seems to be very appropriate because of the ill-defined nature of the domain of study. Moreover, it is also a powerful method that allows reasoning behind the explicit facts provided by the participants in the study. The following study provides an evaluation for AEINS technical features, social aspects in AEINS and the educational outcomes.

\subsubsection{The Study}

A study was conducted with a total of 20 participating children. The study was based on allowing the participants to interact with AEINS in subjective experiences as it is these experiences that need to be captured. The following is a detailed description of the format of the study in addition to a detailed description of the participants. The

\subsubsection{Study Design}

A full study has been completed to test AEINS for different criteria such as the technical infrastructure, its functioning, and its ability to support or enable specific activities, and generate predicted educational outcomes. The study was conducted on a group of children aged 8 to 12 years to test the hypothesis of building an educational game that is able to provide individualized and personalized learning in the ethics domain, and able to develop new thoughts of the participants. Comprehensive log files are automatically generated by AEINS that detailed every action taken within the game. A CRB clearance has been extracted for this purpose.

In designing this study, it was determined that the best approach was to rely on a qualitative research method that produces a description, usually in non-numeric terms ideal for eliciting users' thoughts. Since the participants were children, the use of indepth, open-ended interviewing seemed the appropriate method to capture the interviewees' experiences and getting into their thoughts on the program being evaluated. It helped the participants to express their program experiences and judgments in their own terms. The resulted data consist of verbatim quotations with sufficient context to be interpretable. 
In each assignment, the participant was left to explore and interact with the system at their own pace. The children were monitored during their interaction with AEINS to see if one of the following appears: engagement, losing the feeling about the outside world, boredom, or entertainment. The participants were then postinterviewed, the interviews were semi-structured that composed of open ended questions. All discussions were recorded in order to be analyzed later.

\subsubsection{Participants}

Twenty participants were assigned to play with AEINS over a number of games. Their age was between 8 and 12 years (15 male, 6 female), with an exception of one participant who was a 7 year old. They were all children from schools in York who were recruited through personal contacts and voluntarily agreed to use AEINS after taking their families permission. Table 3 shows that the participants were of different origins and had different cultural backgrounds. The children speak English as their second language; however they were all at the average level of the language skills required for their ages in their classes.

AEINS is built on the universal view of the right and wrong, therefore there was no problem in recruiting children from different back grounds and different cultures as this will not affect how to use AEINS.

Table 3. Demographic data for the participants

\begin{tabular}{|l||c|c|c|}
\hline participants & Gender & Home Country & Age \\
\hline \hline P1 & M & Korea & 11 \\
\hline P2 & F & Fiji & 9 \\
\hline P3 & F & Fiji & 8.5 \\
\hline P4 & F & Fiji & 12 \\
\hline P5 & M & Egypt & 9 \\
\hline P6 & F & Egypt & 11.5 \\
\hline P7 & F & Malissia & 9 \\
\hline P8 & M & Taiwan & 10 \\
\hline P9 & M & Taiwan & 9 \\
\hline P10 & M & Egypt & 10 \\
\hline P11 & M & Egypt & 8 \\
\hline P12 & M & Egypt & 7 \\
\hline P13 & M & Uzbekistan & 8.5 \\
\hline P14 & M & Uzbekistan & 10 \\
\hline P15 & M & Lebanon & 9 \\
\hline P16 & M & Lebanon & 11 \\
\hline P17 & M & Malaysia & 10 \\
\hline P18 & M & Malaysta & 10 \\
\hline P19 & & & \\
\hline P20 & & \\
\hline
\end{tabular}




\subsubsection{Materials and Procedures}

Prior to each experiment, demographic data was collected for each participant and an informed consent form signed by their parents. The participants were interviewed individually. The AEINS environment was briefly introduced to each participant. The participants were encouraged to explore the environment themselves and provided with the required privacy. Participants were explicitly told "Try to be you", our intention is to encourage them to respond on the basis of their moral convictions, without regard for whether an action is good. The participants' reactions during their interaction with AEINS were watched and recorded.

The participants worked at their own pace and all their actions were recorded by AEINS to be analyzed later by us. AEINS did not allow the participant to change their minds regarding their taken actions, because this is what can happen in real life. Once an action is done, there may not be a chance to redo it or revise it. In this way, the participant will experience the effects of his choices on himself and on others in a way similar to that in a real life context.

To evaluate AEINS, post interviews were conducted that focus on five different categories. The first category includes questions related to the technical infrastructure and its functioning. The second category includes questions related to the functions and features inherent in the system and its ability to support or enable a specific activity. The third category includes questions related to the participant tasks. The fourth category includes questions related to the capability for specific technologybased activities to generate predicted outcomes. And finally the fifth category includes questions related to the re-playability and self reflection. The questions in each of these categories are mapped to some other coding questions that are directly related to the research questions needed to be investigated.

We used this style in designing our evaluation, because it was difficult to face the participants with such rich questions that, according to their age range, will be difficult for them to understand. So we substituted research questions with some other questions that can easily be interpreted by the children and allow them to express themselves. The answers to these questions help in answering the main research question in a certain theme, an example of this representation is shown in Table 4ta. This type of assessment allows us to cover different aspects about AEINS and the problem space by ensuring that the participants are assessed on their knowledge of the key moral issues relating to the moral situations they faced.

Table 4. Example of post interview analytical questions 


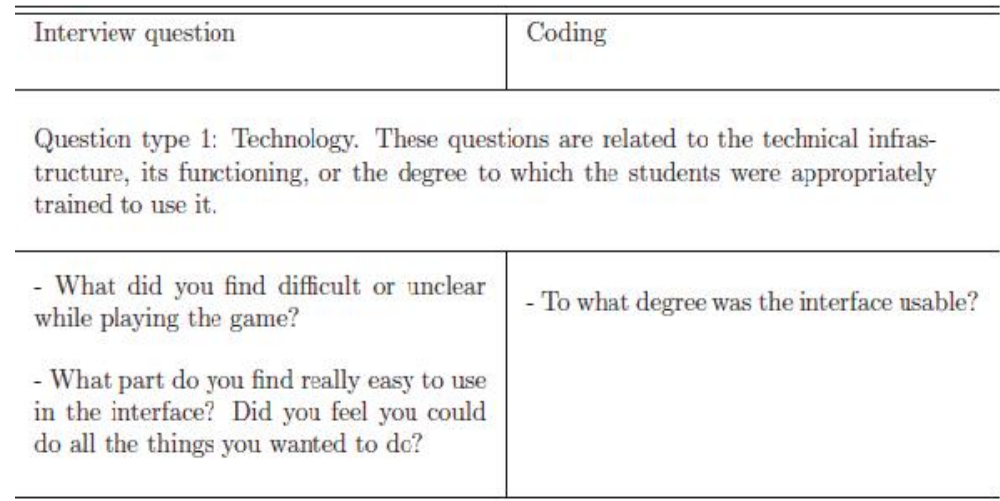

\subsubsection{Results}

According to what AEINS aims to achieve and the data provided, it has been found that it will not be interesting to tackle every single question on its own as sometimes some questions did not produce enough rich data. Instead the results are organized around the main themes reflected by the data. These three themes are: AEINS Architecture and implementation, Social aspects in AEINS, and Learning deployed in AEINS and educational achievements. All the sample comments are representative and no negative comments have been suppressed.

AEINS Architecture and Implementation. The AEINS interface is a simple point and click interface. However, some participants were slow at the beginning getting acquainted to the rules of the game, but after a short time they became quick and very immersed. The interface uses check boxes to handle the student's actions or choices. It allows mouse clicks to interact with the game world and multiple lines text boxes to present the story and stores every single action in the environment. This allows the learner, at any time, to go and see past actions to solve a conflict or judging certain action based on previous ones. Most of the participants referred to the interface as easy to use, one participant commented on the interface saying P18: "Everything is clear. The reading is quite easy, where lines are under each other, quite separate which make things clear." It has been noticed that only a few participants struggle with using the laptop mouse such as P4 and P18, which was easily solved by attaching a normal mouse to the laptop.

Interacting with AEINS was shown to be an enjoyable experience for most of the participants, AEINS was described by P11 as an environment where you can try wrong things and see what could happen. P5 said the following about AEINS “.... very million times good." and added "It tries to make you behave well in real life, this is your training to be good." Another participant said P6: "I enjoyed finding new situations, meeting the characters and solving problems out for them." and added begin \{quote\} "I like the idea of facing situations in different places"

Moreover, the story in AEINS has been described as connected by P5, fun as judged by P13 and by P6 as defined and interesting. Another participant added P18: 
"The whole story is quite organized. It is good and simple.... it gives a variety of options and characters."

The participants asked to have longer time to play with the game adding more situations to interact with and more places (enlarge the environment space) that have realistic pictures with internal views and people acting. This suggests the need for a 3D interface and a bigger world, however it also suggests that they have enjoyed playing with the game and were satisfied with the design of the current moral situations and therefore they are asking for more. In relation to this, the participants were keen to see how the current story (moral situation) will end. This is interesting, because this end represents summative feedback, which is based on all the participant's previous actions in this particular moral dilemma. There are two kinds of feedback, positive feedback in the form of praising the participant for his good attitudes and negative feedback in the form of losing something or losing a friend.

Although AEINS has combined two different techniques to generate the narrative as one of its main contributions. No participant has noticed the transfer points of one technique to another as the story was generated smoothly and successfully to accommodate the teaching moments in a seamless way without affecting the learner's experience. Accordingly, we can say that AEINS manages to compromise between giving the learner the appropriate freedom and being able to track and assess the learning process.

Use of the save facility in AEINS was admired by the participants, they all agreed on the idea of revisiting the experience, for example P6 said "I like saving the experience to remember what happened in case this comes to me again so I remember what I have done" another participant said P1: "I would refer back to the saved stories to check what I have chosen where I can't remember"

We argue that this a critical issue in AEINS, where revisiting the previous experiences allow self-reflection and may judge themselves on the validity of certain actions, in addition to developing or articulating new thoughts and ideas based on existing ones. We think learner's here are attempting the highest levels of the adapted version of Bloom's taxonomy, where they can evaluate actions and develop/create new ideas. This is a recognized result that needs more empirical studies to confirm.

Social Aspects in AEINS. The evaluation shows that children appreciate the social characteristic in the system, as they were able to recognize the genuine social aspects and the realism represented in the game. The analytical questions confirm this recognition. For example, participants clearly cared about the outcome as shown from the following quotes: P15: "The best moment was when my parents and my teacher were proud of me because of what I had done."

Another participant, P16, felt $\{\mid t e x t b f\{\operatorname{good}\}\}$ when the teacher told the parents that he told the truth and he was rewarded by going on a nice summer holiday. This quote and others like P6: "I was $\{\backslash$ textbf $\{$ upset\}\} when my friend said that she will not be my friend anymore." [boldface added] shows the emotional effect of the game on the participants where they can feel good, bad, scared, surprised. Emotional engagement is another positive point AEINS provides.

It seems that AEINS was able to make them feel that they are really involved in realistic situations and consequently they were acting accordingly, which provides more evidence that the participants' were recognizing the social situation and 
recognizing the non-playing characters as real friends. One of the interviewees said P5: "I felt as if I am in a real world and these characters are really talking to me, they were very believable." Another participant said P6: "I did not mean to upset my friend, I felt as if it really happened and I had lost my friend who will not talk to me ever again. I think I will be careful next time."

What was really interesting is the way the participants personalize the non-playing characters in the game. They do not only interact with them as their friends in the game but also they gave them lives and they were picturing how these characters behave beyond these moments. For example, one interviewee said P2: "I do not like Gina when she lies, I want to tell her that this is wrong and she has to stop lying." The interviewee added "If she keeps doing this now, no one will believe her in the future."

The participants also believe the non playing characters' personalities: they like some and dislike others. One participant said P9: "I like Peter the most, he is funny." Another participant said P4: "I do not like Gina, she is not a real friend. She always asks me to do wrong things." and P11: "Gina is a liar." Another participant said P1: "I want to tell Judy to stop acting like a baby"

The realism present in AEINS allows the participants to think about the nonplaying characters as real friends who can feel and expect certain actions from them. For example, one participant quoted P7: "If I choose to be on the side of one friend, the other one could become angry." Another participant, when asked about the nonplaying characters said the following:

P6: "They rely on me. They ask me to solve their problems. They need my help." However, when asked if any of them has behaved in a strange way, he replied "They are trying to make me cheat, real friends do not do this." [italics added]

Moreover, the participants were treating the situations as real ones and responding to them in a realistic way, for example one participant said "I found the homework situation very confusing." and when he has been asked why, he replied P2: "When my mum called me to see the TV, I was scared as I still have homework to do and the teacher will figure out the next morning." [boldface added]

One participant felt proud of herself as she supported her friend and left the football game with him when another player was unfair to this friend. Another participant was very confused in the same situation as she was torn between leaving the game and supporting her friend or missing the fun. [italics added]

These results reflect an important point that the learners were able to react to aspects of the domain and apply their current and potential capacities in this game. From the participants' answers, it has been figured out that most of them were not treating the game as just a game, they do respect and appreciate the difficult situations they were facing and they tried to prove themselves and use their skills in order to solve the discrepancies faced. This is very promising because this means that the actions taken in the game reflect their real beliefs and this will help us to recognize the real effect of AEINS on them. Some quotes reflect this result, for example when one participant mentioned that she does not like the homework teaching moment and when she has been asked why she answered P9: "I do not like doing homeworks" Also another participant had not tried to go home at all and when asked why, he replied P2: "I do not like going home in general." This shows that the children were interacting with AEINS in a realistic manner. 
Although some of the children did not go that far and achieve what their colleagues achieved, we think we are heading in the right direction to tab in this educational field. Some of the children are talking this way and expressing their ideas, P5: "It was really nice solving my friends' problems." P6: "It is good to feel that your friends rely on you, and ask you for help when they need to." This actually can be seen as recognition of abilities and skills of the participants: they felt proud when they succeeded in solving problems and supported their friends. What has been observed here is that the game is not giving certain skills but it empowers the participants to use the skills they have. It also reinforces problem solving skills where learners are forced to solve their friends' problems and helps them to think wisely about the best way to do this, for example this participant did not choose to be on anyone's side as the teaching moment required, he wants to solve the situation by another way as shown in his say P1: "I want to tell them not to be upset, just play, whether to lose or win there is no problem"

These results go well beyond the educational theories that state the importance of stories in transferring tacit knowledge and speak rather about relationships and human connections. In addition, being involved in stories and moral dilemmas helps in emphasizing moral behaviour and gives the chance to experience various situations and allow participants to take different roles.

Learning Deployed in AEINS and Educational Achievements. This theme is very important as it tends to show that AEINS is an effective learning environment and is able to deliver effective learning, in other words, develop the participant's reasoning process. The use of the Socratic Method as the teaching pedagogy shows success. In every teaching moment, since the voice of Socrates comes from one of the involved characters in the moral situation who exhibits certain personality characteristics, mostly one of the learner's friends, to raise the moral conflict, pushes the learner to think harder to solve the discrepancy exist in these situations. For example, from P11's log file, it has been found that the learner followed the following path in the shoplifting dilemma: agree to help his friend to take a chocolate bar without paying for it, then undertake a discussion with the good moral character, who uses Socrate's Voice, the discussion leads to a change in the learner behaviour where he admitted he did a mistake and asked his friend to return the chocolate back. Such an attitude reflects the power of the Socratic Method in forcing the learner to face the contradictions present in any course of action not based on good moral principles. In the post interview with P11, he mentioned that he made a mistake by helping Gina (the immoral character in the shoplifting dilemma) to take the chocolate. This goes well with the results obtained from the log file.

One participant likes the fact that she can interact with the teaching moments and is able to see the effect of her decisions on herself and others. This interviewee has asked to restart the game when she has been faced by negative consequences as a result of one of her choices. This shows that although the feedback was implicitly provided in the story, it manages to deliver the message (you did something wrong) which was not appropriate to be mentioned in an explicit way. In the post interview, it seems that the interviewee has an explicit representation about taking stuff. This appears in her final comment: P13: "Taking other people's stuff is stealing and we should not take something without asking first." 
We claim that the interactive teaching moments were able to provide the appropriate hints about various moral actions and situate the learners in different mental and emotional states. Moreover it allows the learner to attempt the high levels in the adapted version of Bloom's taxonomy such as Analysis, for example the participants were analyzing the situations, where conflict exists, and trying to find a solution to the current dilemma, as in these quotes: P4: "It was difficult to take a decision as this can make my friend upset"'

The participants were also relating to the real world and applying their beliefs, for example participant 17 was nearly choosing all bad actions to do, and accordingly he was faced with negative consequences as a feedback. He said the following in the post interview P17: "I hope if there was no law"" This shows that although he chose to do the bad actions the feedback provided made him think of the law and the consequences of such actions in real life. Another interesting point rose while talking to participant 5 is that they were able to show high intellectual reasoning to provide support to their acts, for example Participant 5 does not like to disagree with his friends as they become angry with him. "I do not want them to stop being my friend." and when asked if they even do wrong things, he replied "Yes, because everyone does wrong stuff."' However, Participant 5 does not seem to be worried about other things rather than losing a friend, we claim that some ideas transfer occurred through interacting with AEINS, the following quote supports this claim "I used to lie on my little sister to come out of trouble, now I think with lying I can be in a bigger trouble." And when asked about what he is going to do now, he answered "Tell the truth."

The presence of the student model provides adaptation in the sense of presenting the teaching moments according to the student's recognized misconceptions. An important point to mention is that this kind of adaptation reinforces re-playability since the student is not presented with all the teaching moments existing in AEINS every time they play. Re-playability can also occur as a result of the variety of the presented teaching moments and the fact of having different branching stories in the single teaching moments. A point was raised by P16 that he would like to try different possibilities for different actions, even if only faced with the same dilemmas he faced before, so he would play daily for about 20 minutes with this game.

We think with the presence of richer repertoire of teaching moments, students can spend a quite long time interacting with AEINS. Such practicing through problem solving and the ability of experiencing new things could lead to developing new insights or deeper ones.

Transferring the knowledge to the real world is the main aim of AEINS although this is very difficult to assess as it needs very long term evaluation. However, the interviews provided some insight about what AEINS has achieved in this area. It has shown that some of the learners are thinking of taking the experiences from the game to real experiments. For example, when one participant was asked about what she thinks she will take away out of this experience, she answered P7: "I will think about the situations I have been involved in and what can happen if I really get involved into one." Another participant commented: P6: "I think this can help me solving school problems." These quotes show the possibility of learning transfer and the sparking of new thoughts and/or deeper ones. This also fits well with [42] in that when people are faced with a new situation in the world, aspects or elements of this 
situation remind them of aspects or elements of experiences they have had in the past. They use these elements of past experience to think about the new situation. Sometimes they can just apply past experience pretty much as is to the new situation, other times they have to adapt past experience to be able to apply it.

Discovery is also another good point AEINS offers as it provides a safe environment for participants to explore. For example, one participant mentioned that he chose to agree with the bad friend in order to see what would happen. On the other hand, another participant thinks that doing a wrong action in the game is just a mistake, but he is aware of not taking the same action in real life. Even this participant has a certain level of awareness, choosing the wrong action in the game will lead to certain consequences that can support his opinion about not to perform the same action in real situations.

\section{Conclusion}

The research done in this paper is a continuation for the literature in the area of educational games and adds more insight into the areas of intelligent tutoring in illdefined domains. The work describes the positive role of integrating individual components that seems to individually have positive effect when employed in educational games. The integrated architecture constitutes a domain model, a student model, a pedagogical model, a presentation module, a story world and story generation modules. The integration allows the presence of a continuous story that acts as the 'glue' between the learning objects (teaching moments). The main contribution of the presented architecture is its ability on providing an engaging narrative experience along with an effective individualized learning process. The architecture has been designed based on learning theories that point out important features that should exist to well-establish the learning environment as well as the learning objects.

We argue that although each individual attribute is not innovative in itself, their integration in one environment is. In ill-defined domains, knowledge to be acquired is more conceptual than perceptual. Accordingly, it is important to provide interaction with just the type of conceptual materials that we want students to learn. An educational game, AEINS, has been developed as a proof-of-concept. AEINS offers the connection between perception and action that is a highly prototypical form of knowledge, represented in the following form of production rules: If this is the current situation, do these. It provides highly engaging environment inhabited with evolving virtual characters with whom the student build relationships and commitments. AEINS is planned to be incorporated within the ethics curriculum at schools. It can assist teachers with its ability of providing summary reports, based on the student model, for individual students. Such reports help the teachers to categorize the students and to identify the students' weak points in a quick and easy way solving time constraints in the classrooms.

AEINS has been intrinsically evaluated to ensure the attempt of all the design goals. AEINS has been evaluated against Gee's games criteria [42] and it has been found that the platform satisfies the majority of these specifications. Qualitative 
measures of motivation and data log files of each participant's interactions with the learning environment were recorded. They confirmed common intuitions about the motivational benefits of educational games. This benefit did not appear to come at the expense of efficiency or quality of learning. We suggest that this motivation to interact with game environments as characterized by high levels of engagement, enjoyment, and perceived challenge may encourage students to continue game-play and ultimately experience higher learning gains. Finally, AEINS has been empirically evaluated considering the following themes: Architecture and implementation, Social aspects, and educational achievements.

AEINS evaluation showed promising results where children were able to build a powerful bridge between their real identity and this virtual identity in the game. They did have emotional responses that transfer their real world responses to the game. This goes quite well with Gee's discussion about learning and identity and his illustration about the importance of the ability of children to build these bridges in order not to make the learning imperiled [43] (p.61). We believe that the interactive dilemmas in AEINS succeeded to induce moral interpretations. What is happening here fits really well with Gee and his theory about "what video games have to teach us" and how learners can be unwilling to put in the effort and practice demanded for mastering a domain if this compelling component is missing [43](p.63). Moreover, the evaluation resulted in useful feedback that helps in modifying the system to be more user friendly and more enjoyable.

Overall, we believe this research provides students with a practical means of exploring abstract issues in concrete settings, allows students to practice making ethical decisions in a realistic context and enables them to see various consequences in a safe environment. Future work includes improving the prototype focusing on three aspects, which are: the addition of more life-like attributes to the agents and emotional modeling, the development of an authoring tool to help teachers and the incorporation of a natural language processing (NLP) engine that might facilitate the student-system interaction.

\section{References}

[1] Lane, H. C. and Core, M. G. and Gomboc, D.and Karnavat, A. and Rosenberg, M.: Intelligent tutoring for interpersonal and intercultural skills. In: the proceedings of Interservice/Industry Training, Simulationand Education Conference (I/ITSEC), pp. 1-11 (2007).

[2] Lynch, C. and Ashley, K. and Pinkwart, N. and Aleven, V.: Argument diagramming as focusing device: does it scaffold reading? In: proceedings of a workshop on AIED Applications in Ill-Defined Domains, held at the 13th International Conference on Artificial Intelligence in Education (2007)

[3] Scandura, J.: Domain Specific Structural Analysis for Intelligent Tutoring Systems: Automatable Representation of Declarative, Procedural and Model-Based Knowledge with Relationships to Software Engineering. Tech, Inst, Cognition and Learning, Vol. 1, pp 7-57 (2003).

[4]Ormerod, T. C.: Planning and ill-defined problems. The Cognitive Psychology of Planning. R. Morris and G. Ward (edts.), Psychology Press. London (2006) 
[5] Lickona, T. and Schaps, E. and Lewis, C.: Eleven Principles of Effective Character Education. In: Character Education Partnership (2007)

[6] McBrien, J. L. and Brandt, R. S.: The Language of Learning: A Guide to Education Terms. Association for Supervision and Curriculum Development, pp. 17-18. Alexandria (1997)

[7] Bolton, G.: Acting in classroom drama: A critical analysis. Heinemann, London (1999)

[8] Shapiro, D. A.: Teaching ethics from the Inside-Out:Some Strategies for Developing Moral Reasoning Skills in Middle School Students. In: proceedings of Seattle Pacific University Conference on the social and Moral Fabric of School Life (1999)

[9] Lane, H. C. Promoting Metacognition in Immersive Cultural Learning Environments. In: Julie A. Jacko (edt.) Human-Computer Interaction, Part IV, pp. 129--139. Springer-Verlag Berlin Heidelberg (2009)

[10] Riedl, M. O. and Young, R. M.: From Linear Story Generation to Branching Story Graphs. In: IEEE Journal on Comput. Graph. Appl., 26(3), pp. 23-31 (2006)

[11] Figueiredo, R. and Brisson, A. and Aylett, R. and Paiva, A.: Emergent Stories Facilitated: An architecture to generate stories using intelligent synthetic characters. In: Proceedings of the $1^{\text {st }}$ Joint International Conference on Interactive Digital Storytelling (ICIDS 2008). Erfurt, Germany (2008)

[12] Harless, W. G.: An Interactive Videodisc Drama: The Case of Frank Hall. Journal of Computer-Based Instruction, 13(4) (1986)

[13] Bradford, W. M. and Charles, B. C. and Luke, S. Z. and Seung, Y. L. and James, C. L. and Muriel, R.: Towards narrative-centered learning environments. In M. Mateas and P. Sengers (edts.), Narrative Intelligence: Papers from the 1999 Fall Symposium. Menlo Park, CA: American Association for Artificial Intelligence, pp. 78-82 (1999)

[14] Waraich, A.: Using narrative as a motivating device to teach binary arithmetic and logic gates. SIGCSE Bull Journal, 36(3), pp. 97-101 (2004)

[15] Johnson, W. and Marsella, L. S. and Vilhjálmsson, H.: The DARWARS Tactical Language Training System. In: Proceedings of the $26^{\text {th }}$ Interservice/Industry Training, Simulation, and Education Conference (I/ITSEC). Orlando, FL. (2004)

[16] Vilhjalmsson, H. and Merchant, C. and Samtani, P.: Social Puppets: Towards Modular Social Animation for Agents and Avatars. In: Online Communities and Social Computing. Lecture Notes in Computer Science, pp. 192--201. Springer Berlin / Heidelberg (2007)

[17] Thomas, J. M. and Young, M.: Becoming Scientists: Employing Adaptive Interactive Narrative to Guide Discovery Learning. In: proceedings of AIED-07 Workshop on Narrative Learning Environments. Marina Del Rey, California, USA (2007)

[18] Mott, B. W. and Lester, J. C.: U-director: a decision-theoretic narrative planning architecture for storytelling environments. In: Proceedings of the $5^{\text {th }}$ international joint conference on Autonomous agents and multi-agent systems (AAMAS'06), pp. 977-984. Hakodate, Japan (2006)

[19] McQuiggan, S. and Rowe, J. and Lee, S. and Lester, J.: Story-Based Learning: The Impact of Narrative on Learning Experiences and Outcomes. In: Proceedings of the Ninth International Conference on Intelligent Tutoring Systems(ITS-2008)\}. Montreal, Canada (2008)

[20] Prada, R. and Machado, I. and Paiva, A.: Teatrix: A Virual environment for story Creation. In: Intelligent Tutoring Systems. Gauthier and C. Frasson and K. Van Lehn (edts.). Springer (2000)

[21] Riedl, M. and Stern, A.: Believable Agents and Intelligent Story Adaptation for Interactive Storytelling. In: 3rd International Conference on Technologies for Interactive Digital Storytelling and Entertainment. Darmstadt, DE (2006)

[22] Bayon, V. and Wilson, J. and Stanton, D. and Boltman, A.: Mixed reality storytelling environments. Virtual Reality Journal, 7(1) (2003) 
[23] Aylett, R. and Vala, M. and Sequeira, P. and Paiva A.: FearNot! - An Emergent Narrative Approach to Virtual Dramas for Anti-bullying Education. In: proceedings of International Conference on Virtual Storytelling 2007, pp. 202-205 (2007)

[24] Magerko, B. S. and Stensrud, B. S.: Bringing the schoolhouse inside the box-a tool for engaging, individualized training. In: Proceedings of $25^{\text {th }}$ Army Science Conference. Orlando, FL. (2006)

[25] Mckenzie, A. and Mccalla, G.: Serious Games for Professional Ethics: An Architecture to Support Personalization. In: Workshop on Intelligent Educational Games - AIED 2009. Brighton, UK. (2009)

[26] Dettori, G. and Paiva, A.: Narrative Learning in Technology-Enhanced Environments. In: Technology-Enhanced Learning. S. Ludvigsen and N. Balacheff and T. de Jong and A. Lazonder and S. Barnes (edts.). Springer (2009)

[27] Conati, C. and Manske, M.: Evaluating Adaptive Feedback in an Educational Computer Game. In IVA 2009, pp. 146-158 (2009)

[29] Pierce, N. and Conlon, O. and Wade, V.: Adaptive Educational Games: Providing Noninvasive Personalised Learning Experiences. In: Proceedings of the $2^{\text {nd }}$ IEEE International Conference on Digital Game and Intelligent Toy Enhanced Learning (2008)

[30] Elkind, D. H. and Sweet, F.: How to do character education (1997), http://www.goodcharacter.com/Article_4.html\},

[31] Avner, A. and Moore, C. and Smith, S.: Active external control: A basis for superiority of CBI. Journal of Computer-Based Instruction, 6(4), pp. 115-118 (1980)

[32] Lynch, C. and Pinkwart, N. and Ashley, K. and Aleven, V.: What Do Argument Diagrams Tell Us About Students' Aptitude Or Experience? A Statistical Analysis In An Ill-Defined Domain. In: Proceedings of the workshop on Intelligent Tutoring Systems for 11l-Defined Domains, held at the $9^{\text {th }}$ Intenational Conference on Intelligent tutoring Systems. Montreal, Canada (2008)

[33] Mergel, B.: Occasional papers in educational technology. University of Saskatchewan (1998), http://www.usask.ca/education/coursework/802papers/mergel/brenda.htm

[34] Sklar, E.: Agents for education: when too much intelligence is a bad thing. In: Proceedings of the 2nd International Joint Conference on Autonomous agents and Multi-agent Systems, pp. 1118-1119. Elbourne, Australia (2003)

[35] Conati, C. and Zhao, X.: Building and evaluating an intelligent pedagogical agent to improve the effectiveness of an educational game. In: proceedings of the 9th international conference on Intelligent user interfaces, pp. 6-13. Funchal, Madeira, Portugal (2004)

[36] Kuhn, D.: Science as argument: implications for teaching and learning scientific thinking.

Journal of Science Education, 77(3), pp. 319-337 (1993)

[37] Oliver, M.: An introduction to the evaluation of learning technology. Journal of Educational Technology and Society, 3(4) (2000)

[38] Karpov, I. V., D'silva, T., Varrichio, C., Stanley, K. O. and Miikkulainen, R.: Integration and evaluation of exploration-based learning in games. In: IEEE Symposium on computational Intelligence and Games, pp. 21-24 (2006)

[39] Malone, T. W. and Lepper, M. R.: Making learning fun: A taxonomy of intrinsic motivations for learning. In: R. E. Snow and M. J. Farr (edts.) Aptitude, learning, and instruction: Vol. 161 III. Cognitive and affective process analyses, pp. 229-253. Erlbaum. Hillsdale, NJ (1988)

[40] Carroll, J. M., Singley, M. K. and Rosson, M. B.: Integrating theory development with Design Evaluation. Journal of Behaviour and Information Technology,11, pp. 247-255 (1992)

[41] Gena, C.: Methods and techniques for the evaluation of user adaptive systems. Journal of Knowledge Engineering Review, 20(1), pp. 1-37. Cambridge University Press (2005) 
[42] Gee, J. P.: Learning by design: Games as learning machines. IEM: Interactive Educational Multimedia, 8, pp.15-23 (2004)

[43] Gee, J. P.: Are video games good for learning?. Keynote address at Curriculum Corporation $13^{\text {th }}$ National Conference. Adelaide (2003)

\section{Appendix: A Typical Student-System Interaction Scenario}

This appendix presents a typical scenario that the children might have encountered playing the game, showing the role of the characters, different modules' roles and some typical teaching moments. The system's interaction is in normal font. The student's actions are in bold. Comments and illustrations are italicized.

At the very beginning the system allows the learner to enter his name and pick a character to represent him/her in the game world. Then the system greets him/her and presents a brief introduction about the game world.

Hi Rania! This is your world, please have a look around!

You have four places to go to: the house, the shop, the library and the school.

There are four characters with whom you can make friends.

You have a list of actions to choose your actions from.

You are free to play whenever you are ready.

Now, it is time to choose your friends...

The system presents the characters by name and personalities

The user has to choose a categorized yes/no answer, as no free text is allowed in the current version of AEINS

Gina is a nice girl, she is sincere. Gina does not accept taking things without permission but she can lie.

Do you like Gina and want to be her friend?

Yes

You like Gina. You and Gina are friends now.

Peter is a beloved boy, he is good and sincere but sometimes he cheats.

Do you like Peter and want to be her friend?

No

You do not like Peter. You and Peter are not friends.

Judy is a beautiful girl, she does not accept to lie or to take things without permission. Judy is sometimes not sincere to her friends.

Do you like Judy and want to be her friend?

No

You do not like Gina. You and Judy are not friends. 
John is a funny boy, he is popular. John does not lie but sometimes he can take stuff that is not his.

Do you like John and want to be his friend?

Yes

You like John. You and John are friends now.

After the student chooses his friends, the student model is initialized according to these choices. The following facts are now asserted in the student model ( $\sim$ denotes 'not')

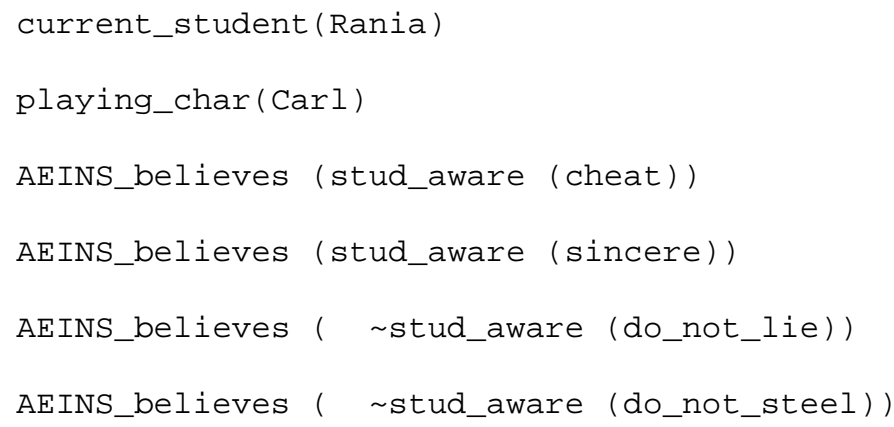

Based on the above information and that of the domain model, the student model infers new facts as follows:

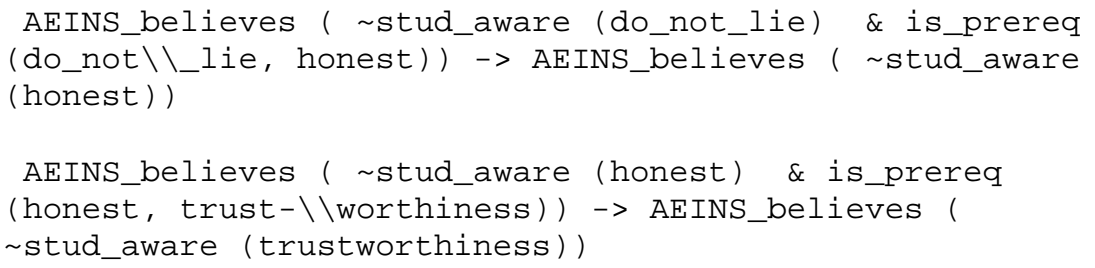

The student model is updated by adding the new drawn facts to the current model.

Based on the current student model, the pedagogical model chooses a teaching moment:

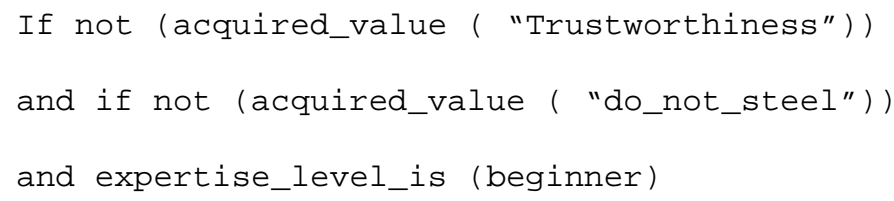




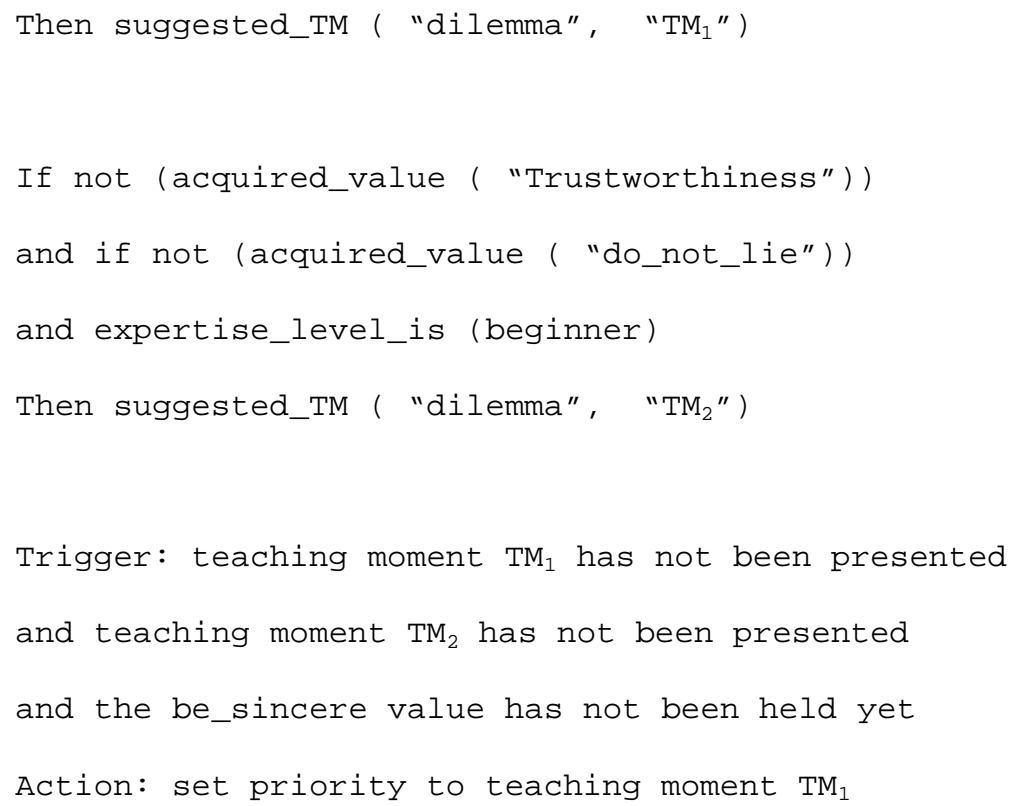

It is worth at this point to remind the reader that every teaching moment has two kinds of prerequisites: educational and narrative. The educational prerequisites have been satisfied from the above rules leading the pedagogical model to choose the teaching moment $\left(T M_{1}\right)$ to present to the student.

It is now time to satisfy the narrative prerequisites that allows the teaching moment to be presented as a part of the continuous story.

The pedagogical model send the teaching moment id to the story generator that fetches the narrative preconditions for the required dilemma. These prerequisites are as follows:

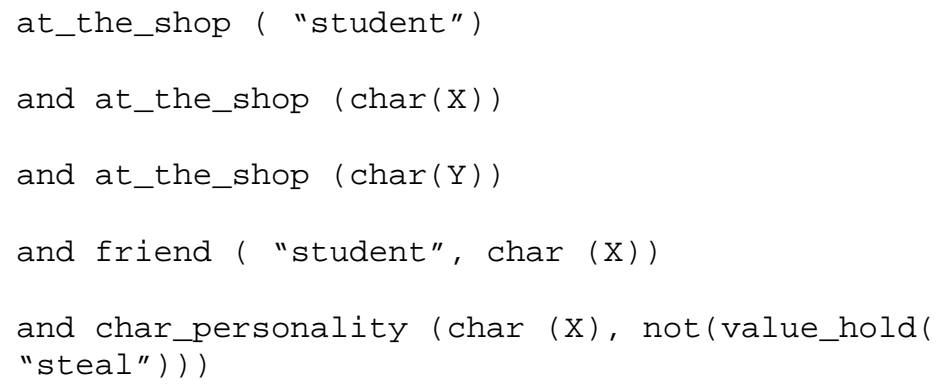




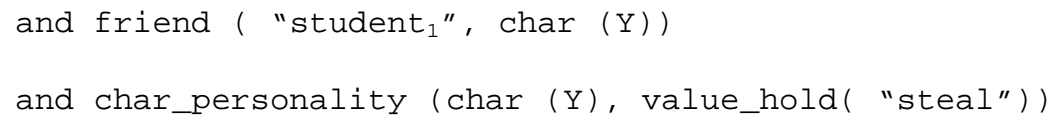

The story generator considers these prerequisites as the current goals and generates a plan that allows the story to unfold from the current world state to the goals state.

Now AEINS asks the learner to either act or allow AEINS to act.

Please choose an action or press done for the system's turn.

The learner chooses to act, he chooses to invite someone to his house (this is done by choosing one of the actions: the student chooses "invite home".

The system now asks the user to choose whom he wants to invite and then press the "carry my action button."

Now CLICK on whom you want to invite to your home. Then press CARRY OUT MY ACTION button.

The learner chooses to invite Gina (this is done by clicking on Gina's picture.)

You chose to invite Gina.

Since the agents inhabiting AEINS world are semi-autonomous, they are able to reply directly to the student's latest action through the reactive planner. The reactive planner chooses the highest preference action for the agent. Based on the current status of the student and the agent the following action executes.

Gina accepts your invitation.

Gina is at your house.

AEINS asks the learner to either act or allow AEINS to act.

Now choose another action or press done for the system's turn.

The learner chooses to allow AEINS to act (this is done by pressing the done button.)

As it is AEINS turn to act, the STRIPS-like planner executes the first action in the previously generated plan. Since Gina is already involved in the story and exhibits the required properties required by the narrative prerequisites, the story world does not need to introduce a new character at this stage.

Gina: I am going to the store now.

Gina is at the store.

AEINS asks the learner to either act or allow AEINS to act. 
Now choose another action or press done for the system's turn.

The learner chooses to allow AEINS to act. To satisfy one of the goals, the story world introduces Judy that satisfies the required conditions.

Judy: I like you and want to be your friend, do you agree?

Yes.

You agreed to be friend to Judy.

AEINS asks the learner to either act or allow AEINS to act.

Now choose another action or press done for the system's turn.

The learner chooses to allow AEINS to act: As the narrative preconditions still miss the presence of another agent with the student at the required place, the following action will be executed.

Judy: I am the store, do you want to come and join me?

Yes.

You agreed to join Judy.

AEINS asks the learner to either act or allow AEINS to act.

Now choose another action or press done for the system's turn.

The narrative preconditions of the teaching moment have now been satisfied, the learner and two friends of his are all at the store. Since the preconditions and actions are represented by variables, this allows different characters to join the learner in the future. The teaching moment starts as follows:

Gina is looking around in the store and they saw the kind of chocolate they like.

Gina has no enough money to buy the chocolate

Gina has an idea!! they can take the chocolate if you helped them to distract the shop_keeper.

Gina: Could you please help me and distract the shopkeeper's attention? I really want that chocolate bar.

Yes.

You agreed.

AEINS reflects on the user's action by stressing on his chosen action.

You helped Gina to take the chocolate.

AEINS recognizes that the learner's attitude is not a desirable one. Therefore, Judy, the one who holds the do_not_steal principle, will start the Socratic Dialogue in this dilemma aiming to guide the student to figure out why his action was not right. 
Judy: I do not like what you did, this is not good. Am I right?

No.

You disagreed.

The teaching moment unfolds according to the student's answers to Judy. Judy will follow the Socratic Dialogue and raise the ante when necessary as follows:

Judy: It is really bad to take stuff that is not ours without permission. You will be a law breaker, do you agree?

No.

You disagreed.

Judy: I am surprised as you do not think that people who take things which are not theirs deserve to be punished. I wonder what if the shop was yours, will you still think the same?

No.

You disagreed.

Judy: It seems that you only care about your own things and not about others, am I right?

No.

You disagreed.

Judy: I do not think you do really care. If you do you would not harm people by taking their stuff without their permission. Am I right?

No.

You disagreed.

Judy: I will not be your friend any more if you insist on what you did. Now, do you want to tell Gina to return the chocolate back?

Yes.

You agreed.

Judy: I admire what you did. As you see, the shopkeeper caught Gina and punishes her for what she did.

The teaching moment ends at this point and the pedagogical model assessed the student's actions as follows:

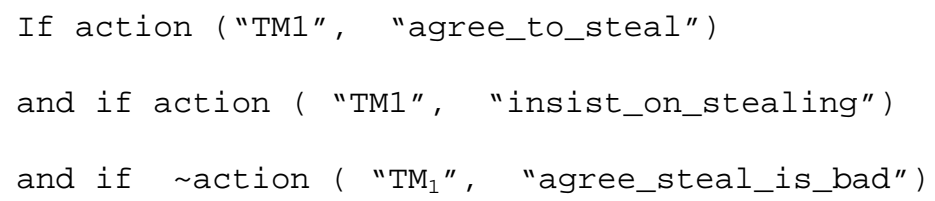




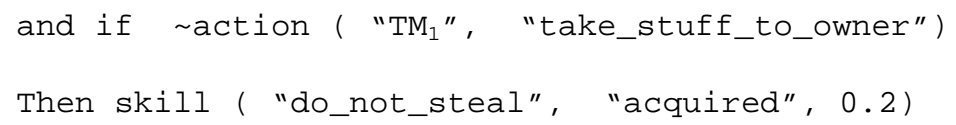

The value 0.2 is the system's confidence of the gained skill, which is lower than a prespecified threshold in this example. Based on this information the pedagogical model updates the student model by asserting the following rule(s):

skill ( "do_not_steal", "not_acquired", 0.8)

According to the updated student model, the student has misconceptions with the do_not lie value (old piece of information from the instantiated student model at the beginning of the game) and the do_not_steal value (new information from the updated model). Based on this information the pedagogical model can choose either a teaching moment that deals with the same value (do_not_steal) or a teaching value that considers the (not_lie) value as follows:

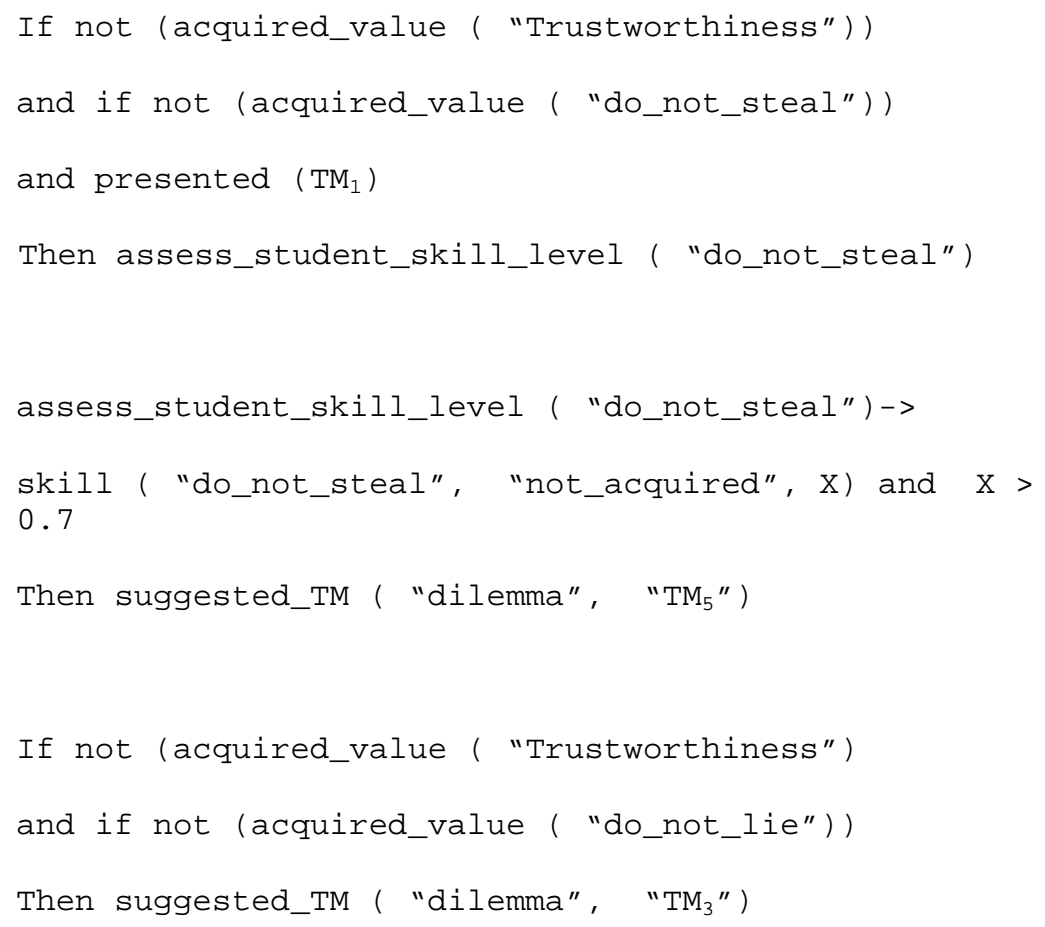

It is worth to mention that these are non-deterministic rules where more than one solution can be obtained. According to the fired rules, two teaching moments are 
suggested: $T M_{3}$ and $T M_{5}$. The current pedagogical model chooses randomly one of the teaching moments to present. The chosen teaching moment id will be send to the story generator to construct a new plan.

Now AEINS asks the learner to either act or allows AEINS to act.

Please choose an action to perform or press done for the system's turn.

AEINS continues interacting with the learner based on the student model. 